\title{
Qualidade dos medicamentos contendo dipirona encontrados nas residências de Araraquara e sua relação com a atenção farmacêutica
}

\author{
Eliana Ometto Pavan Serafim ${ }^{1}$, Adriana del Vecchion', Juliana Gomes ${ }^{1}$, Aline Miranda' \\ Andréia de Haro Moreno ${ }^{2}$, Leonor Monteiro de Castro Loffredo ${ }^{1}$, \\ Hérida Regina Nunes Salgado², Man Chin Chung ${ }^{1,2^{*}}$
}

\begin{abstract}
${ }^{1 *}$ Lapdesf - Laboratório de Pesquisa e Desenvolvimento de Fármacos, Departamento de Fármacos e Medicamentos, Faculdade de Ciências Farmacêuticas, Universidade Estadual "Júlio de Mesquita Filho", Araraquara, 2 Departamento de Fármacos e Medicamentos, Faculdade de Ciências Farmacêuticas, Universidade Estadual "Júlio de Mesquita Filho", Araraquara
\end{abstract}

* Correspondence

M. C. Chung

Departamento de Fármacos e

Medicamentos

Faculdade de Ciências Farmacêuticas Universidade Estadual Paulista "Júlio de Mesquita Filho"

Rodovia Araraquara-Jaú, km 01 14801-902 - Araraquara - SP, Brasil

E-mail: chungmc@fcfar.unesp.br
Vários estudos relatam a ocorrência de morbi-mortalidade relacionada com medicamentos. Quanto às estratégias para reduzir possíveis riscos à terapia medicamentosa é de suma importância a necessidade de reorientação da atividade farmacêutica, uma vez que o profissional farmacêutico tem potencial para se constituir em uma parte essencial para a solução dos problemas relacionados à utilização de medicamentos. $O$ objetivo deste trabalho foi demonstrar que o fator subdosagem terapêutica e a contaminação microbiana podem estar diretamente envolvidos com a manipulação inadequada dos medicamentos mantidos nas residências. Medicamentos líquidos contendo dipirona comercializados no Brasil e armazenados em residências em Araraquara (SP) foram avaliados no que se refere a análises quantitativa e microbiológica. Somente em 57\% das 128 amostras analisadas a quantidade de fármaco estava de acordo. Além disso, 26,2\% das 128 amostras analisadas apresentaram S. aureus, E. coli e Salmonella sp. Esses resultados demonstraram clara queda na qualidade dos mesmos, assim como a presença de fungos elou bactérias em alguns dos medicamentos, que ainda estavam dentro de seus prazos de validade, demonstrando a importância do profissional farmacêutico na orientação quanto ao uso e ao armazenamento correto do medicamento.
Unitermos

- Atenção farmacêutica

- Estabilidade

- Dipirona

- Araraquara

\section{INTRODUÇÃO}

O conceito de Atenção Farmacêutica segundo Hepler e Strand (1999) "é a prestação responsável da farmacote- rapia com o propósito de alcançar resultados definidos que melhorem a qualidade de vida dos pacientes". Assim sendo, os medicamentos são administrados para alcançar os seguintes resultados específicos: cura da doença, redução 
ou eliminação dos sintomas, detenção ou diminuição do progresso da doença e a prevenção da enfermidade. Para tal, o farmacêutico deve seguir três princípios fundamentais: identificar problemas reais e potenciais relacionados com os medicamentos, resolver problemas reais e prevenir os problemas potenciais. Assim, quando transferimos esses conceitos para a prática cotidiana, podemos dizer que o farmacêutico presta assistência farmacêutica quando analisa as necessidades do paciente, relacionadas com os medicamentos, determina se o paciente tem um ou mais problemas reais ou potenciais relacionados com os medicamentos e quando trabalha com o paciente e com outros profissionais de saúde do paciente para controlar o uso dos medicamentos, promovendo a saúde e prevenindo enfermidades com a finalidade de garantir que o tratamento farmacológico seja seguro e efetivo. Deste modo, consolida a relação existente entre a prática e o conhecimento teórico na atuação farmacêutica. Segundo os autores, diferentes estudos relatam a ocorrência de morbi-mortalidade relacionada com medicamentos.

Quanto às estratégias para reduzir possíveis riscos à terapia medicamentosa, Hepler e Strand (1999) destacam a necessidade de reorientação da atividade farmacêutica. Afirmam que, por sua situação profissional, geográfica e social, os farmacêuticos têm potencial para se constituir em uma parte essencial para a solução dos problemas relacionados à utilização de medicamentos, uma vez que possuem contato direto com o paciente.

De fato, não existem estudos que relacionem diretamente a prevalência de morbi-mortalidade relacionada com medicamentos ao tipo ou à qualidade dos serviços farmacêuticos disponíveis, mas alguns relatos demonstram que estes serviços podem reduzir notavelmente os custos totais de assistência e hospitalização (Hepler, Strand, 1999).

Os problemas relacionados ao medicamento podem ser classificados de diversas maneiras. Aceita-se, inclusive, como parâmetro para a Organização Mundial de Saúde, a classificação elaborada no Consenso de Granada (2000) de forma a relacionar os problemas a três grandes campos de necessidades:

1. a necessidade de que os medicamentos estejam indicados;

2. a necessidade de que os medicamentos sejam efetivos e

3. a necessidade de que os medicamentos sejam seguros. No campo $\mathrm{n}^{\circ} 2$, um problema relacionado bastante importante é o verificado quando os pacientes se utilizam de tratamentos com medicamentos em doses inferiores às necessárias, com diversas causas para isso.

Uma das causas mais diretamente envolvidas é a interrupção de tratamentos indevidamente. Outra bastante importante é a subdosagem por problemas encontrados nos medicamentos, quer seja por falhas de produção ou por processos envolvendo a estabilidade das preparações farmacêuticas. Os fármacos podem ter sua estabilidade afetada por processos destrutivos, tanto na hidrólise, no qual os mesmos interagem com moléculas de água formando produtos com composição química diferente quanto à oxidação, que destroem muitos tipos de moléculas do fármaco, ocorrendo alteração na sua cor, propriedades organolépticas e precipitação.

O processo de hidrólise provavelmente é a principal causa de decomposição do fármaco, uma vez que grande número de princípios ativos é formado por ésteres ou contém outros grupamentos como amidas substituídas e lactonas, que são suscetíveis ao processo hidrolítico (Friis, Bundgaard, 1996).

Outros processos destrutivos, como a polimerização, descarboxilação química e desaminação nas preparações farmacêuticas também podem ocorrer. A instabilidade das formulações farmacêuticas pode ser detectada em casos de mudança na aparência física, cor, odor, gosto ou textura; em outros casos podem ocorrer alterações químicas, que não são aparentes e que só podem ser verificadas por análise química (Genaro, 2000).

Para a aprovação de um medicamento são necessários os vários testes de estabilidade. Entretanto, esses medicamentos podem sofrer alterações caso não sejam armazenados corretamente. Desta forma, o objetivo deste trabalho foi demonstrar que o fator da subdosagem pode estar diretamente envolvido com a manipulação inadequada do medicamento na residência. Desta forma, foram realizados estudo quantitativo e análise microbiológica de medicamentos contendo dipirona, mantido em residências de Araraquara.

\section{MATERIAL E MÉTODOS}

\section{Amostras do estudo}

O experimento foi realizado em 477 residências na cidade de Araraquara (SP), em bairros de diferentes classes sociais, como Jardim Primavera (classe A), Santa Angelina (classe B), São José (classe C), Vila Xavier (classe D) e Vale do Sol (classe E), com o preenchimento de um formulário (Quadro 1), aquisição de medicamentos contendo dipirona (em gotas) a serem analisados e a entrega de folheto educativo (Quadro 2) como orientação de descarte dos medicamentos.

Das 477 entrevistas, foram coletadas 142 amostras. Os formulários foram pré-codificados, permitindo melhor identificação dos dados. O programa estatístico emprega- 
QUADRO 1 - Questionário utilizado nas entrevistas realizadas nas residências

\section{Questionário No.}

Bairro:

Endereço:

Identificação

1) Idade:

2) Sexo: ( ) M ( ) F

3) Número de pessoas na casa: ( ) crianças ( ) adultos ( ) idosos

4) Alguém com doença crônica: ( ) S ( ) N, se sim qual o remédio:

Dipirona

1) Possui dipirona em casa: ( ) $\mathrm{S} \mathrm{(} \mathrm{)} \mathrm{N}$

2) Qual o nome do remédio:

3) Como armazena os medicamentos em casa:

4) Como é o descarte:

5) Há quanto tempo: ( ) 1 ano ou mais ( ) 6 meses ( ) 1 mês

6) Segue a bula: () $\mathrm{S}($ ) $\mathrm{N}$

7) Quem indicou a dipirona: ( ) Farmacêutico ( ) Amigo ( ) Médico ( ) Balconista

8) Quando toma dipirona:

Geral

1) Conhece a profissão farmacêutica: ( ) $\mathrm{S}$ ( ) $\mathrm{N}$

2) Conhece os remédios genéricos: ( ) $\mathrm{S}($ ) $\mathrm{N}$

3) Possui remédios vencidos: ( ) S ( ) N

4) Compra remédios com receita: () $\mathrm{S}$ ( ) $\mathrm{N}$

Obs.:

QUADRO 2 - Informações contidas no folheto educativo como orientação para o descarte de medicamentos

\section{ORIENTAÇÃO PARA O ARMAZENAMENTO E DESCARTE DE MEDICAMENTOS}

\section{DESCARTE}

\section{Medicamentos vencidos}

Líquidos: devem ser dispensados em água corrente (pia, tanque ou vaso sanitário), sendo a embalagem descartada diretamente no lixo após lavagem, com exceção dos antibióticos, que devem ser encaminhados, preferencialmente, a alguma farmácia ou local responsável pela coleta.

Sólidos (comprimidos, tabletes, drágeas): podem ser dissolvidos em água e dispensados em água corrente (pia, tanque ou vaso sanitário) ou enterrados.

\section{Medicamentos especiais}

Controlados (tarja preta), antimicrobianos, hormônios, citostáticos, antineoplásicos, imunossupressores, digitálicos, imunomoduladores, anti-retrovirais devem ser encaminhados para local responsável pela coleta (Vigilância Sanitária, Postos de Saúde, Prefeituras, etc.).

\section{ARMAZENAMENTO}

Todos os medicamentos devem ser armazenados em locais protegidos da luz, da umidade, calor, radiação e do alcance das crianças.

Não deixá-los em locais como pias, banheiros, armários próximos a janelas, fogões ou a fornos de microondas. Lavar bem as mãos antes de qualquer manuseio com medicamentos.

Não deixar frascos abertos ou desprotegidos a fim de evitar contaminação ou degradação.

Nunca armazenar medicamentos juntamente com alimentos.

\section{ATENÇÃO !}

Não utilizar medicamentos com sinais de degradação ou deterioração, tais como: odor alterado, mudança de coloração e/ou consistência, formação de bolhas ou gases, ressecamento ou formação de sedimento ou precipitado. 
do foi o EPI-INFO, versão 6.04. A determinação quantitativa do fármaco foi realizada segundo a Farmacopéia Brasileira (1976).

\section{Técnicas e procedimentos}

\section{Instrumentação básica}

Todas as pesagens foram realizadas utilizando-se uma balança analítica Gehaka, modelo BG400 com precisão de $1 \mathrm{mg}$.

Todas as soluções destinadas às investigações titulométricas foram preparadas utilizando vidraria de laboratório grau $\mathrm{A}$.

\section{Obtenção das amostras}

As amostras foram obtidas mediante coleta de medicamentos contendo dipirona nas residências e analisadas quanto ao teor de princípio ativo e contaminação microbiológica. Foram utilizadas como controle amostras comerciais adquiridas e abertas para o ensaio.

\section{Preparo das amostras e procedimento experimental}

As amostras contendo dipirona na forma líquida (solução oral) foram analisadas diretamente. Alíquotas de $0,4 \mathrm{~mL}$ de cada medicamento (equivalente a $200 \mathrm{mg}$ de dipirona) foram tomadas com auxílio de pipetador automático e diluídas em 5,0 $\mathrm{mL}$ de água desionizada; adicionouse volume de $5,0 \mathrm{~mL}$ de ácido clorídrico $0,02 \mathrm{~N}$ e titulouse com solução de iodo $0,1 \mathrm{~N}$, empregando solução de amido como indicador. Os experimentos foram realizados em triplicata. A determinação quantitativa foi realizada segundo a Farmacopéia Brasileira (1976).

\section{Reagentes e soluções}

Solução de $\mathrm{HCl}$ 0,02 $\mathrm{N}$ : preparado a partir de uma solução a $1 \mathrm{~N}$ (85 mL de ácido clorídrico p.a. Merck em balão de $1000 \mathrm{~mL}$ e completado o volume com água desionizada). Foi utilizada uma alíquota de $20,00 \mathrm{~mL}$ da solução a $1 \mathrm{~N}$, transferida para balão volumétrico de $1000 \mathrm{~mL}$ e completado o volume com água desionizada.

Solução de iodo 0,1 N: dissolveram-se cerca de $14 \mathrm{~g}$ de iodo em solução de $36 \mathrm{~g}$ de iodeto de potássio em $100 \mathrm{~mL}$ de água; juntaram-se 3 gotas de ácido clorídrico pa, completou-se o volume com água a $1000 \mathrm{~mL}$. Padronização: pesaram-se exatamente cerca de $150 \mathrm{mg}$ de trióxido de arsênio pa e dissolveu-se em $20 \mathrm{~mL}$ de $\mathrm{NaOH} 1 \mathrm{~N}$ aquecendo, se necessário. Diluiu-se com 40 mL de água, juntaramse 2 gotas de alaranjado de metila e a seguir com ácido clorídrico diluído SR até viragem do amarelo para rosa. Juntaram-se $2 \mathrm{~g}$ de bicarbonato de sódio p.a., diluiu-se com $50 \mathrm{~mL}$ de água e juntaram-se $3 \mathrm{~mL}$ de amido. Titulou-se com solução de iodo $0,1 N$ até cor azul. Cada 4,946 mg de trióxido de arsênio equivale a $1 \mathrm{~mL}$ de iodo $0,1 \mathrm{~N}$.

Solução de amido (indicador): para o preparo do indicador amido pesaram-se 5,00 g de amido solúvel Merck e acrescentaram-se $10 \mathrm{~mL}$ de água desionizada, fazendo uma pasta. Transferiu-se essa pasta para um béquer contendo 500,0 $\mathrm{mL}$ de água desionizada quente e ferveu-se em bico de Bunsen até a solução tornar-se clara. Utilizou-se somente o sobrenadante como indicador. As soluções empregadas na determinação de dipirona foram preparadas segundo Farmacopéia Brasileira (1976), Harris (1999) e Morita e Assunção (2000).

\section{Controle Microbiológico}

A segunda etapa do projeto consistiu no controle microbiológico dos medicamentos para a determinação do número total de microrganismos e pesquisa de Salmonella sp, Escherichia coli, Pseudomonas aeruginosa e Staphylococus aureus. Foram analisadas 21 amostras (que continham quantidade suficiente) conforme métodos preconizados na Farmacopéia Brasileira (1988), British Pharmacopeia (2001) e USP 25 (2002).

\section{Contagem do número total de microrganismos}

Foi transferido, assepticamente, $1 \mathrm{~mL}$ de cada amostra para $9 \mathrm{~mL}$ de solução tampão fosfato $\mathrm{pH} 7,2$, para a contagem dos microrganismos totais. A diluição 1:10 foi submetida à agitação durante $10 \mathrm{~min}$. Após a homogeneização, foi pipetado $1 \mathrm{~mL}$ da diluição 1:10 e adicionados $20 \mathrm{~mL}$ de ágar tioglicolato e ágar Sabouraud (para bactérias e fungos ou leveduras, respectivamente) a $47^{\circ} \mathrm{C} \mathrm{em}$ placas de Petri, que foram colocadas em estufa a $35^{\circ} \mathrm{C}$ por $24 \mathrm{~h}$ e $25^{\circ} \mathrm{C}$ por 7 dias, para a pesquisa de bactérias e fungos, respectivamente. Após este período, foi realizada a contagem do número de colônias, com o auxílio de contador automático de colônias, calculando o número de Unidades Formadoras de Colônias (UFC).

\section{Pesquisa de Salmonella sp e Escherichia coli}

Foi transferido, assepticamente, $1 \mathrm{~mL}$ de cada amostra para $9 \mathrm{~mL}$ de caldo lactosado, para pesquisa de Salmonella e E. coli. Incubou-se o caldo a $35^{\circ} \mathrm{C}$ durante 24 a $48 \mathrm{~h}$. Após este período, $1 \mathrm{~mL}$ do caldo lactosado foi transferido para 2 tubos contendo caldo tetrationato e caldo selenito cistina, que foram incubados a $35^{\circ} \mathrm{C}$ durante $24 \mathrm{~h}$. Após este período, a amostra foi semeada do caldo tetrationato para 1 tubo contendo ágar verde brilhante e duas placas de Petri contendo ágar XLD e ágar bismuto sulfito. Foi realizado da mesma forma com a amostra inoculada no caldo selenito cistina, transferindo para os três meios, os quais foram incubados a $35{ }^{\circ} \mathrm{C}$ durante $24 \mathrm{~h}$. $\mathrm{O}$ crescimen- 
to e as características das colônias foram observados. As colônias suspeitas foram semeadas com alça reta em tubo contendo ágar TSI e incubado a $35^{\circ} \mathrm{C}$ durante $24 \mathrm{~h}$. A confirmação da Salmonella foi feita pelo método de Gram.

Na pesquisa de E. coli, $1 \mathrm{~mL}$ do caldo lactosado foi transferido para placa contendo ágar MacConkey e incubado a $35^{\circ} \mathrm{C}$ durante $24 \mathrm{~h}$. As colônias suspeitas foram semeadas em ágar EMB e incubadas a $35^{\circ} \mathrm{C}$ durante $24 \mathrm{~h}$. A confirmação da $E$. coli foi realizada através de método de Gram.

Pesquisa de Staphylococcus aureus e Pseudomonas aeruginosa

Foi transferido, assepticamente, $1 \mathrm{~mL}$ de cada amostra para $9 \mathrm{~mL}$ de caldo soja-caseína, para a pesquisa de $S$. aureus e $P$. aeruginosa e incubados a $35^{\circ} \mathrm{C}$ por 24 a $48 \mathrm{~h}$. Após este período, com auxílio de alça de platina, foi semeado em ágar Vogel Johnson, para a pesquisa de $S$. aureus e ágar cetrimida, para a pesquisa de $P$. aeruginosa a $35^{\circ} \mathrm{C}$ durante $24 \mathrm{~h}$. As características das colônias foram observadas e a confirmação foi realizada através de método de coloração de Gram.

\section{RESULTADOS E DISCUSSÃO}

A maioria dos entrevistados (45\%) pertence à faixa etária de 50 a 70 anos, sendo de sexo feminino (75\%). Verificou-se que grande parte dos entrevistados citaram 2 adultos morando em sua residência, sem doença crônica (78,3\%). Somente 6,9\% disseram sofrer de hipertensão.

Observou-se que a maior parte dos moradores utiliza medicamentos contendo dipirona, sendo os mais utilizados Anador ${ }^{\circledR}$ e Novalgina ${ }^{\circledR}$. Quanto ao local de armazenamento dos medicamentos, os entrevistados utilizam gavetas, dispensas, pias, dentro de caixas ou de armários, ou mesmo em caixas dentro de armários e ao ar livre. Constatou-se que a maioria é guardada dentro de armários na cozinha (Figura 1) e ignoram o tempo de armazenamento do medicamento depois de aberto, assim como a sua exposição a altas temperaturas, luz solar ou artificial e umidade; muitas vezes os frascos não são corretamente fechados, sendo o conta-gotas colocado diretamente em contato com pias e mesas ou mesmo com as mãos; entretanto não possuem medicamentos vencidos em suas residências $(93,3 \%)$ e o descarte é realizado diretamente ao lixo (79\%), conforme mostrado na Figura 2.

Não foi possível estabelecer uma relação entre classe econômica e resultados encontrados, porém verificou-se que moradores de bairros mais carentes praticamente não possuíam medicamentos armazenados em suas residências, possivelmente devido ao baixo poder aquisitivo ou di- fícil acesso aos mesmos, enquanto moradores de bairros mais privilegiados apresentaram número maior de medicamentos em suas residências. Entretanto, houve dificuldades de acesso aos moradores dos bairros mais nobres (geralmente ausentes no momento da visita ou recusando receber as informações), diferentemente da população mais carente, os quais receberam maior número de orientações e folhetos informativos.

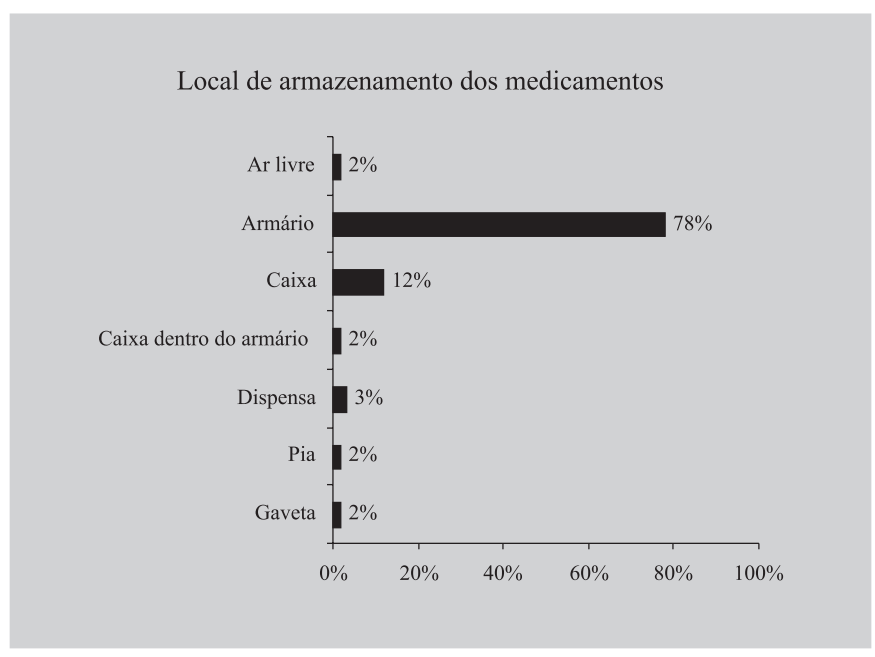

FIGURA 1 - Local de armazenamento dos medicamentos relatados pelos entrevistados.

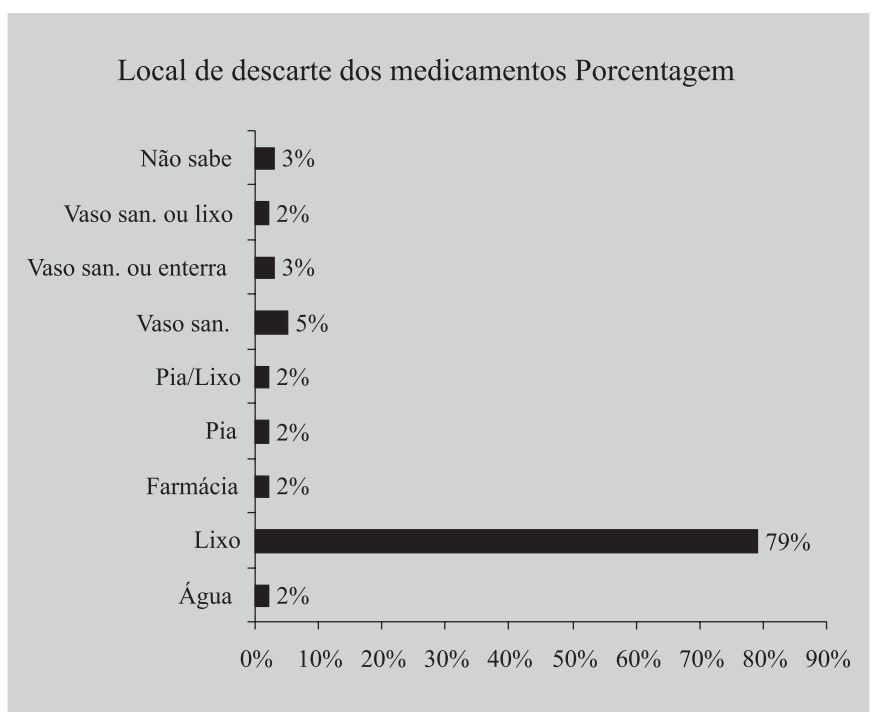

FIGURA 2 - Local de descarte dos medicamentos relatados pelos entrevistados.

Os entrevistados utilizam medicamentos por aconselhamento médico e os adquirem com receita médica $(83,3 \%) ; 75 \%$ utilizam a bula como instrução e $41 \%$ utilizam medicamentos contendo dipirona quando apresentam cefaléia e $17 \%$ quando apresentam febre. A Figura 3 mos- 
tra os sintomas relatados pelos entrevistados para a utilização do medicamento.

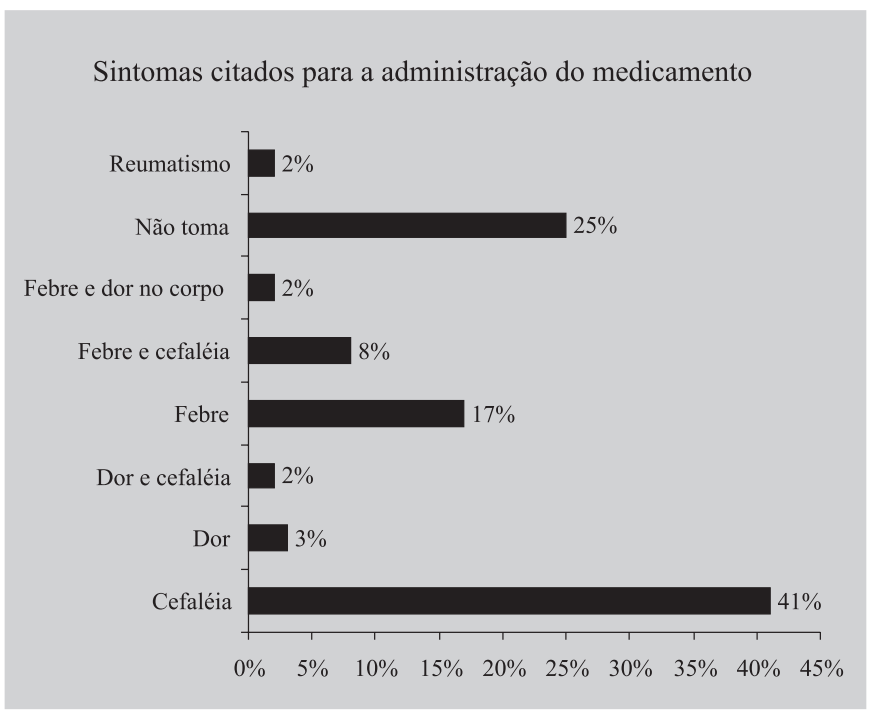

FIGURA 3 - Sintomas relatados pelos entrevistados para a utilização de dipirona.

O profissional farmacêutico é conhecido pelos entrevistados e cerca de $80 \%$ conhecem os medicamentos genéricos. Os teores de dipirona encontrados nas amostras analisadas dos medicamentos abertos coletados nas residências demonstraram que há perdas de até $42,6 \%$ nos medicamentos quando comparados com controle (amostra comercial adquirida e aberta para o ensaio) conforme representado na Figura 4. O teor de dipirona encontrado para o controle foi de $99,8 \pm 0,3 \%$, representando seis determinações $(n=6)$.

Teor de dipirona nos medicamentos

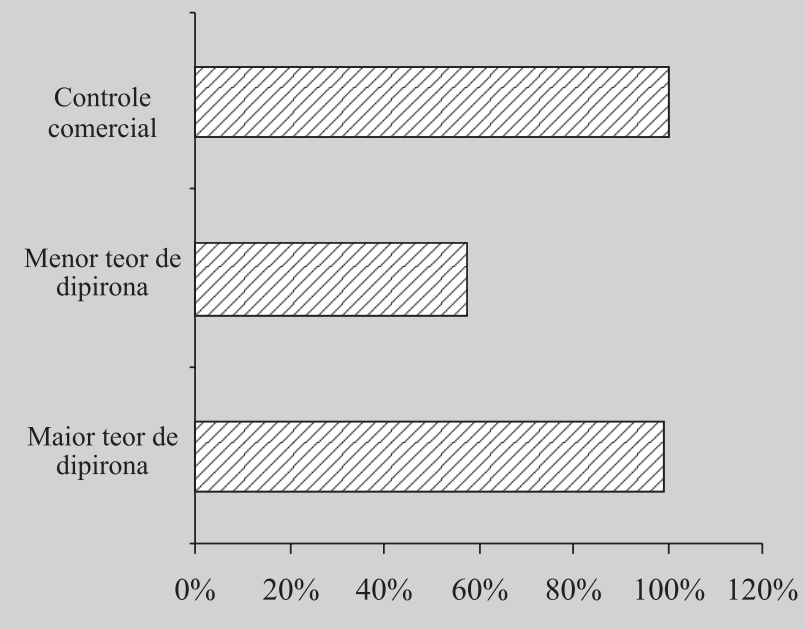

FIGURA 4 - Teor de dipirona encontrado nas amostras coletadas nas residências
Foram analisadas amostras de medicamentos contendo dipirona de diversas marcas comerciais, como Anador $^{\mathbb{R}}$ (Boehringer Ingelhein), Baralgin ${ }^{\circledR}$ (Glaxo Wellcome), Dipigina $^{\circledR}$ (Belfar), Dipimax ${ }^{\circledR}$ (Cimed), Dipiron ${ }^{\circledR}$ (Medquímica), Dipirona ${ }^{\circledR}$ (Furp), Dipirona sódica ${ }^{\circledR}$ (EMS), Dipirona sódica ${ }^{\circledR}$ (Basf Generix), Dipirona sódica ${ }^{\circledR}$ (Teuto), Dipirona sódica ${ }^{\circledR}$ (Donaduzzi Prati), Dorona ${ }^{\circledR}$ (Ducto), Dorspan ${ }^{\circledR}$ (EMS), Lisador ${ }^{\circledR}$ (Farmasa), Magnopyrol $^{\circledR}$ (Farmasa), Maxiliv ${ }^{\circledR}$ (Ache), Metamizol ${ }^{\circledR}$ (PM/SPCentro Farmac.), Neosaldina ${ }^{\circledR}$ (Knoll), Nofebrin ${ }^{\circledR}$ (Legrand), Novalgina ${ }^{\circledR}$ (Hoechst) e Sedalo Composto ${ }^{\circledR}$ (Hipolabor).

A Tabela I representa os resultados obtidos para as amostras analisadas segundo o método da Farmacopéia Brasileira (1976).

Conforme verificado na Tabela I, os resultados obtidos para produto aprovado encontram-se em conformidade com as especificações farmacopéicas para produto acabado ( $10 \%$ do valor nominal). Assim, para as amostras contendo $500 \mathrm{mg} / \mathrm{mL}$ de dipirona (valor nominal), são aceitos teores compreendidos na faixa de 450 a $550 \mathrm{mg} / \mathrm{mL}$ ou de 90,0 a $110,0 \%$; os produtos reprovados não apresentaram resultados compreendidos nesta faixa de aceitação, sendo os resultados, na maioria das vezes, muito menores que o mínimo estabelecido ( $450 \mathrm{mg} / \mathrm{mL}$ ou $90,0 \%$ ), demonstrando subdosagem e ineficácia terapêutica.

As amostras de dipirona analisadas apresentaram contaminação microbiológica, tendo sido detectado $S$. aureus, E. coli e Salmonella sp, microrganismos considerados patógenos e, portanto, devendo estar ausentes em preparações para uso interno, além de grande número de fungos e leveduras em $26,2 \%$ das amostras analisadas.

Os resultados obtidos revelaram a instabilidade dos fármacos nos medicamentos dentro do prazo de validade, armazenados nas residências, atingindo até $42,6 \%$ de perda no teor dos medicamentos analisados quando comparados às amostras-controle, representando perda considerável para se poder estabelecer a possível relação entre armazenamento e manipulação inadequados e teores baixos de princípio ativo quando considerado que todos os medicamentos tenham sido previamente aprovados nos respectivos controles de qualidade físico-químico e microbiológico.

Embora existam diversos mecanismos de degradação das moléculas dos fármacos, os processos de instabilidade mais comuns são: oxidação, hidrólise, redução, fotólise ou fotodegradação e racemização, acelerados por fatores como temperatura, presença de oxigênio, luz, radiação e umidade (Gil et al., 2005; Nudelman, 1975). Muitos podem ser observados através de mudança de cor, formação de precipitados e evolução de gases, porém a maioria dessas 
TABELA I - Resultados das determinações do teor de dipirona obtidos de amostras coletadas em vários bairros do município de Araraquara (SP)

\begin{tabular}{ccccc}
\hline \multirow{2}{*}{ Medicamento } & \multicolumn{2}{c}{ Aprovados } & \multicolumn{2}{c}{ Reprovados } \\
\hline A & Encontrado $(\mathrm{mg} / \mathrm{mL})$ & Porcentagem $(\%)$ & Encontrado $(\mathrm{mg} / \mathrm{mL})$ & Porcentagem $(\%)$ \\
B & $473,78 \pm 10,66$ & $94,75 \pm 2,13$ & $395,54 \pm 23,10$ & $79,11 \pm 4,62$ \\
C & $450,00 \pm 10,90$ & $90,00 \pm 2,18$ & - & - \\
D & $469,46 \pm 7,23$ & $93,89 \pm 1,44$ & - & - \\
E & $459,17 \pm 6,29$ & $91,83 \pm 1,26$ & - & - \\
F & - & - & $387,50 \pm 6,61$ & $77,50 \pm 1,32$ \\
G & $480,55 \pm 11,12$ & $96,11 \pm 2,22$ & $411,31 \pm 11,26$ & $82,26 \pm 2,25$ \\
H & $513,39 \pm 13,10$ & $102,68 \pm 2,62$ & $402,5 \pm 33,78$ & $80,50 \pm 6,75$ \\
I & $509,17 \pm 11,81$ & $101,83 \pm 2,36$ & - & - \\
J & - & - & $335,00 \pm 15,00$ & $67,00 \pm 3,00$ \\
L & - & - & - & $89,00 \pm 2,65$ \\
M & $469,72 \pm 18,23$ & $93,94 \pm 3,65$ & - & - \\
N & - & - & $348,33 \pm 26,50$ & $69,67 \pm 5,30$ \\
O & - & $228,31 \pm 6,01$ & $68,56 \pm 1,80$ \\
P & $486,33 \pm 11,69$ & $97,27 \pm 2,34$ & - & - \\
Q & $459,17 \pm 11,81$ & $91,83 \pm 2,36$ & - & - \\
R & $495,00 \pm 16,39$ & $99,00 \pm 3,28$ & - & - \\
S & - & - & $178,25 \pm 2,84$ & $59,42 \pm 0,95$ \\
T & $483,33 \pm 13,77$ & $96,67 \pm 2,75$ & - & - \\
U & $462,81 \pm 6,70$ & $92,56 \pm 1,34$ & $513,54 \pm 30,11$ & $102,71 \pm 6,02$ \\
\hline
\end{tabular}

* Conteúdo descrito para os medicamentos: $500 \mathrm{mg} / \mathrm{mL}$

* Total de medicamentos aprovados: 93

* Total de medicamentos reprovados: 35

* Total de medicamentos analisados: 128

incompatibilidades químicas resultantes de alterações ou rearranjos moleculares não são visivelmente observáveis (Orth, 1989).

Para os produtos não-estéreis a influência de fatores como manuseio, falta de higiene, armazenamento e tempo de exposição do produto aberto é de extrema importância, principalmente devido à grande suscetibilidade de contaminação microbiológica, uma vez que os produtos apresentam veículo aquoso e diversas fontes orgânicas de carbono, hidrogênio e oxigênio, representadas pelos componentes a base de açúcares, gomas e outros (Nudelman, 1975). A luz e o calor podem degradar os conservantes do produto, o fechamento inadequado do frasco pode tornar-se uma via de entrada de novos microrganismos vindos do ambiente e, devido à perda de escamas da pele por parte de diferentes usuários (na ordem de $10^{4}$ por minuto em atividades normais), diversos microrganismos podem estar presentes em função dos seus hábitos de higiene (Pinto et al., 2003). Além disso, a substância ativa pode ser degradada de forma direta através da ação de microrganismos sob a molé- cula do fármaco, ou de forma indireta, alterando o $\mathrm{pH}$ eleito e, conseqüentemente, dissociando a molécula (Orth, 1989).

O descarte inadequado de medicamentos também é um fator preocupante, uma vez que podem apresentar risco à saúde de crianças ou pessoas carentes que venham possivelmente reutilizá-los. Para tanto, é de suma importância a orientação da população quanto ao correto descarte dos mesmos.

\section{CONCLUSÃO}

De acordo com o conceito de atenção farmacêutica como sendo a prestação responsável da farmacoterapia com o propósito de alcançar resultados definidos que melhorem a qualidade de vida dos pacientes, este trabalho demonstrou que o papel do farmacêutico não se limita em simplesmente dispensar o medicamento, mas também, de orientar a população no armazenamento correto dos mesmos, pois além da diminuição da atividade terapêutica, pode ocorrer a formação de produtos de degradação tóxi- 
cos, alergênicos e irritantes ao organismo e a contaminação dos produtos pela exposição inadequada.

O conceito mais amplamente difundido para Atenção Farmacêutica foi formulado em 1990 definido como sendo “a provisão responsável do tratamento farmacológico com o propósito de alcançar resultados concretos que melhorem a qualidade de vida do paciente. Estes resultados são: 1) a cura da enfermidade, 2) a eliminação ou redução da sintomatologia do paciente, 3 ) o controle do progresso de uma enfermidade e 4) a prevenção de uma enfermidade ou sintomatologia" (Hepler e Strand, 1999).

Desta forma, em Atenção Farmacêutica o acompanhamento do paciente é fator preponderante e este trabalho demonstra a sua grande importância, uma vez que o medicamento armazenado pode conter teores abaixo dos valores estabelecidos, embora dentro do prazo de validade, não promovendo a atividade terapêutica esperada. Também, é importante alertar os fabricantes quanto à necessidade de estudos de prazo de validade para os medicamentos após sua abertura (rompimento do lacre).

\section{AGRADECIMENTOS}

Agradecemos à Maria do Rosário Guerra Araújo, pelo auxílio técnico, e à AFAR- Associação Farmacêutica de Araraquara, pela doação dos medicamentos contendo dipirona.

\section{ABSTRACT \\ Analysis of medicines and the relationship with pharmaceutical care: quantitative and microbiological determination of medicines containing dipyrone}

Many studies had described the morbi-mortality related to medicines. As for the strategies to reduce the possible risks for medicine therapy is very important to readvise the pharmaceutical activity, once the pharmacist has potential for constitute an essential part for the solution of problems related to the utilization of medicines. The purpose of this work was to demonstrate that the therapeutic subdosage and the microbiological contamination may be directly involved with the inappropriate manipulation of medicines stored in residences. Liquid dosage forms containing dipyrone market in Brazil and stored at homes in Araraquara (SP) were analyzed regarding quantitative and microbiological analysis. Only in 57\% from 128 samples analyzed the drug quantity was in accordance. Moreover, 26.2\% from 128 samples analyzed presented $\mathrm{S}$. aureus, E. coli and Salmonella sp. These results demonstrated clear reduction in their quality, as well as the presence of molds and/or bacteria in some medicines that still agreed with the expirations dates, showing the importance of the pharmacist in advising the correct use and store of medicines.

UNITERMS: Pharmaceutical care. Stability. Dipyrone. Araraquara.

\section{REFERÊNCIAS BIBLIOGRÁFICAS}

BRITISH Pharmacopoeia. 2001. London: The Stationery Office, 2001.v.1,p.A303-A314.

FARMACOPÉIA Brasileira 3.ed. São Paulo: Organização Andrei, 1976. p.406-408.

FARMACOPÉIA Brasileira .4.ed. São Paulo: Atheneu, 1988. pt.1, p.v.5.1.6.-v.5.1.7.-6.

FRIIS, G.J.; BUNDGAARD, H. Design and application of prodrugs. In: KROGSGAARD-LARSEN, P.; LILJEFORDS, T.; MADSEN, U.A., (Eds.). A textbook of drugs design and development. 2.ed. Harwood: Academic Publishers, 1996. p.540-547.

GENARO,A.R.,(Ed.). Remington: The science and practice of pharmacy. $20^{\text {th }}$. ed. Philadelphia: Lippincott Williams \& Wilkins, 2000. p.439-460.

GIL, E.S.; ORLANDO, R.M.; MATIAS, R.; SERRANO, S.H.P. Controle físico-químico de qualidade de medicamentos. Campo Grande: Uniderp, 2005. p.287292.

HARRIS, D.C. Análise química quantitativa. 5. ed. New York: LTC , 1999. p.150-167.

HEPLER, C.D.; STRAND, L.M. Oportunidades y responsabilidades de la atención farmacéutica. Pharm. Care, v.1, n.1, p.35-47, 1999.

MORITA, T.; ASSUNÇÃO, R.M.V. Manual de soluções reagentes e solventes, padronização - preparação purificação. São Paulo: Edgard Blucher, 2001. p.56-61.

NUDELMAN, N.E.S. Estabilidad de medicamentos. Buenos Aires: El Ateneo, 1975. p.23-61. 
ORTH, D.S. Microbiological considerations in cosmetics formula development and evaluation. Cosm. Toiletries, v.104, n.4, p.49-64, 1989.

PINTO, T.J.A.; KANEKO, T.M.; OHARA, M.T. Controle biológico de qualidade de produtos farmacêuticos, correlatos e cosméticos. 2. ed. São Paulo: Atheneu, 2003. p.37-44.
UNITED States Pharmacopea. 2002. Washington: United States Pharmacopeial Convention, 2002. p.1873-1878.

Recebido para publicação em 01 de fevereiro de 2006. Aceito para publicação em 29 de março de 2007. 